\title{
Morphological aspects of mural thrombi deposition residual lumen route in infrarenal abdominal aorta aneurisms ${ }^{1}$
}

\author{
Morfologia da deposição de trombos murais: trajeto da luz residual em aneurismas de \\ aorta abdominal infra-renal
}

\begin{abstract}
Thiago Adriano Silva Guimarães ${ }^{\mathrm{I}}$, Guilherme Nobrega Garcia' ${ }^{\mathrm{II}}$, Marcelo Bellini Dalio ${ }^{\mathrm{III}}$, Matheus Bredarioli ${ }^{\mathrm{III}}$, Cleber Aparecido Pita Bezerra ${ }^{\text {III }}$, Takachi Moriya ${ }^{\text {IV }}$

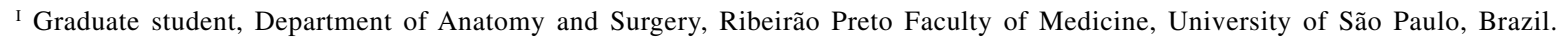

${ }^{\text {II }} \mathrm{MD}$, Resident physician in General Surgery, Department of Surgery and Anatomy, Ribeirão Preto Faculty of Medicine, University of São Paulo, Brazil.

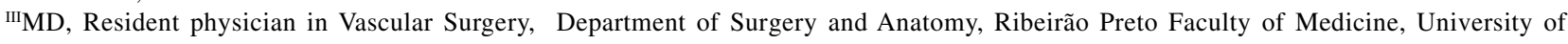
São Paulo, Brazil.

${ }^{\text {IV }} \mathrm{PhD}$, Professor, Department of Surgery and Anatomy, Ribeirão Preto Faculty of Medicine, University of São Paulo, Brazil.
\end{abstract}

\begin{abstract}
Purpose: To assess the most frequent deposition site of mural thrombi in infrarenal abdominal aorta aneurisms, as well as the route of the residual lumen. Methods: Assessment of CT scan images from 100 patients presenting asymptomatic abdominal aorta aneurism, and followed at HC-FMRP-USP. Results: In 53\% of the cases the mural thrombus was deposited on the anterior wall; from these, in $22 \%$, the residual lumen described a predominantly right sided route; in $22 \%$, a left sided route; on the mid line in 5\%; and crossing over the mid line in $1 \%$. In $23 \%$, the deposition of thrombi was concentric. In $11 \%$ it occured on the posterior wall; from these, in 5\%, the route of the residual anterior lumen was predominantly right sided; in 5\%, left sided; and crossed over the mid line in 1\%. In 13\% complex morfological deposition patterns were found. Conclusion: Mural thrombi formation was predominantly found on the anterior wall of the aneurismatic mass, with the route of the residual lumen projecting towards the posterior wall.
\end{abstract}

Key-words: Abdominal Aorta Aneurisms. Thrombi and CT Scan.

\section{RESUMO}

Objetivos: Avaliar o local mais freqüente de deposição do trombo mural em aneurismas de aorta abdominal infrarenal, bem como o trajeto da luz residual. Métodos: Avaliação de tomografias de 100 pacientes do HC-FMRP-USP apresentando aneurisma de aorta abdominal assintomático. Resultados: O trombo mural se deposita na parede anterior em 53\% dos casos, sendo que a luz residual posterior descreveu um trajeto predominantemente à direita em $22 \%$ dos casos, à esquerda em $22 \%$, na linha mediana em $5 \%$ e cruzando da direita para a esquerda em $4 \% .23 \%$ dos casos apresentaram deposição concêntrica do trombo e $11 \%$ apresentaram deposição na parede posterior, sendo o trajeto da luz residual anterior predominante a direita em 5\% dos casos, a esquerda em 5\% e cruzando a linha mediana em 1\%. Padrões morfológicos complexos de deposição do trombo foram encontrados em 13\% dos casos. Conclusão: A formação do trombo mural predominou na parede anterior da massa aneurismática, com o trajeto da luz residual se projetando para a parede posterior.

Descritores: Aneurisma de Aorta Abdominal. Trombo e Tomografia Computadorizada por Raios X.

1. Study conducted at the Division of Angiology and Vascular Surgery, Department of Surgery and Anatomy, Ribeirao Preto Faculty of Medicine, University of São Paulo, Brazil. 


\section{Introduction}

Abdominal aorta aneurisms (AAA) are found in 4.3 to $8 \%$ of male patients above 60 and in 0.4 to $1.8 \%$ of female patients in this same age group. ${ }^{1-3}$ The rupture of the aneurism is the most dramatic event, being associated with 50 to $75 \%$ mortality rates, significant morbidity and high costs for the individual, the family and society. AAA causes 15,000 deaths per year in the United States, and its incidence does not decrease over time. ${ }^{4-9}$

An intraluminal thrombus (ILT) is present in approximately $75 \%$ of all cases of AAA. ${ }^{10}$ Recent studies suggest that the ILT is an active pathogenic factor for AAA. ${ }^{11-12}$ Adolph et al, ${ }^{11}$ have demonstrated the biological activity of the thrombus by the presence of activated cells and by the relative permeability of the aneurismatic wall to formed elements of the blood. Fontaine et $\mathrm{al}^{12}$ have indicated the enzymatic activity concentrated in mural thrombi as a likely relevant factor in the course of aneurisms.

However, its influence on the outcome of the aneurism is still a matter of controversy. Some authors have suggested that the thrombus would function as a protecting factor for the aneurismatic wall against the hemodynamic stress,${ }^{10}$ others report the thrombus as a factor predisposing to rupture ${ }^{13}$ and associate it with the weakening of the aneurismatic wall. ${ }^{14-15}$

\section{Objective}

We have assessed CT scan images from patients followed-up at the HC-FMRP-USP for non-ruptured AAAs, with a focus on the morphology of the thrombi and the aneurism residual lumen route, seeking to find defined distribution patterns.

\section{Methods}

\section{Study population}

This study included 100 asymptomatic patients diagnosed with non-ruptured infrarenal aneurism of the aorta, and followed-up at the Angiology \& Vascular Surgery Dept. of the Ribeirao Preto Medical School General Hospital, USP, in period from 1998 to 2005.

\section{Statistical analysis}

Our data were separately compared with two other published reports - Pillari et $\mathrm{al}^{16}$ and Hans et $\mathrm{al}^{17}$ - using the chi-square test. Such comparisons were conducted separately due to the difficulties in pooling together the three reports in one single analysis. This happened because the sample sizes were different and because, in our report, we included one additional category, i.e., complex thrombi.

\section{CT scans}

We analyzed five sections, taken at 20-mm intervals from the $100 \mathrm{~mm}$ of abdominal aorta before the iliac arteries bifurcation and below the renal arteries emergence.

The images were taken with the following CT equipment: conventional, 3rd generation Philips Tomoscan LX, with 320x320 matrix, section thickness of $10 \mathrm{~mm}, 10-\mathrm{mm}$ displacement, $120 \mathrm{KV}$ and $270 \mathrm{mAs}$; helicoidal Siemens Emotion with 512x512 matrix, section thickness of $5 \mathrm{~mm}, 5$ $\mathrm{mm}$ displacement, reconstruction interval $7.5 \mathrm{~mm}, 130 \mathrm{KV}$ and $110 \mathrm{mAs}$; and conventional Siemens Somaton with continuous rotation, $512 \times 512$ matrix, section thickness of $10 \mathrm{~mm}, 10-\mathrm{mm}$ displacement, $130 \mathrm{KV}$ and $70 \mathrm{mAs}$.

We used as a pattern the segmentation of the images in four quadrants, in addition to anterior, posterior, right, left and central spots, as shown on Figure 1, and the aneurisms were categorized according to the residual lumen disposition.

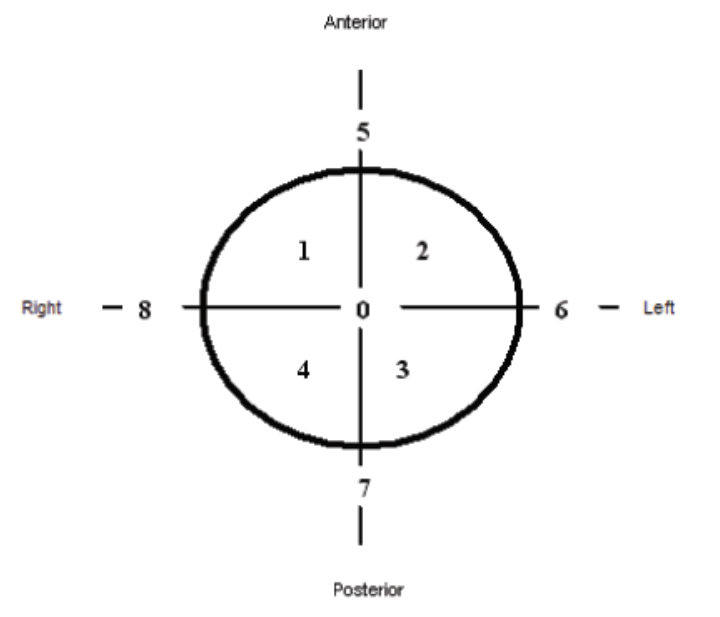

FIGURE 1 - Assessment pattern.

\section{Results}

The mural thrombus was found mainly on the anterior wall $(53 \%) ; 13 \%$ were on the posterior wall and $14 \%$ were concentrically deposited. From all the ILT assessed, $11 \%$ displayed a complex formation, alternating from anterior to posterior, without a clearly defined pattern; $9 \%$ of the images showed no mural thrombus (Figure 2). 


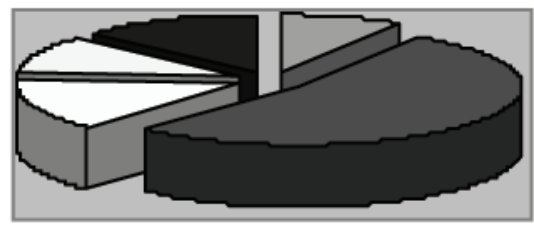

$\square$ No thrombus $\square$ Anterior wall $\square$ Concentric $\square$ Posterior wall $\square$ Complex

FIGURE 2 - Disposition of mural thrombi.

For those images showing an anterior intraluminal thrombus, the residual lumen's route was located in the right lower quadrant or in the left lower quadrant, 22 cases $(41.5 \%)$ each. In 5 patients $(9.4 \%)$, the residual lumen ran along the lower mid line; in 4 patients $(8.6 \%)$ it crossed from the right to the left quadrant (Figure 3).
In patients with intraluminal thrombus on the posterior wall, the lumen projected towards the right upper quadrant in 5 cases $(45.5 \%)$, the same number observed in the left upper quadrant. In one patient $(9 \%)$, the anterior lumen route crossed the mid line (Figure 3).

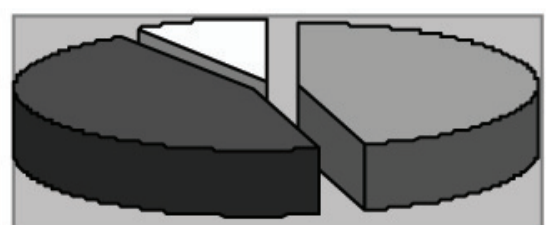

$\square$ Right anterior lumen

Left anterior lumen

$\square$ Anterior lumen crossing mid line

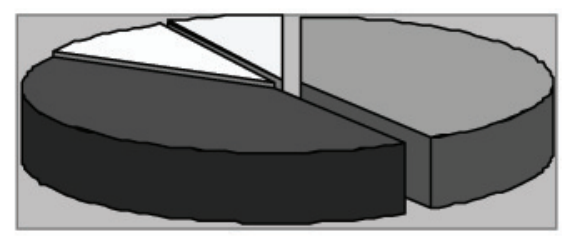

$\square$ Right posterior lumen

Left posterior lumen $\square$ Mid posterior lumen

$\square$ Posterior lumen crossing mid I

FIGURE 3 - Lumen route in patients with anterior mural thrombus and lumen route in patients with posterior mural thrombus.

In 23 patients, the lumen followed a central route. Fourteen had concentric mural thrombi and 9 had thrombifree abdominal aneurisms (Figure 2).
In 13 patients, the images showed an AAA with a mural thrombus deposited without a specific pattern, crossing the mid line, in the anterior-posterior direction (Figures 2 and 4). 

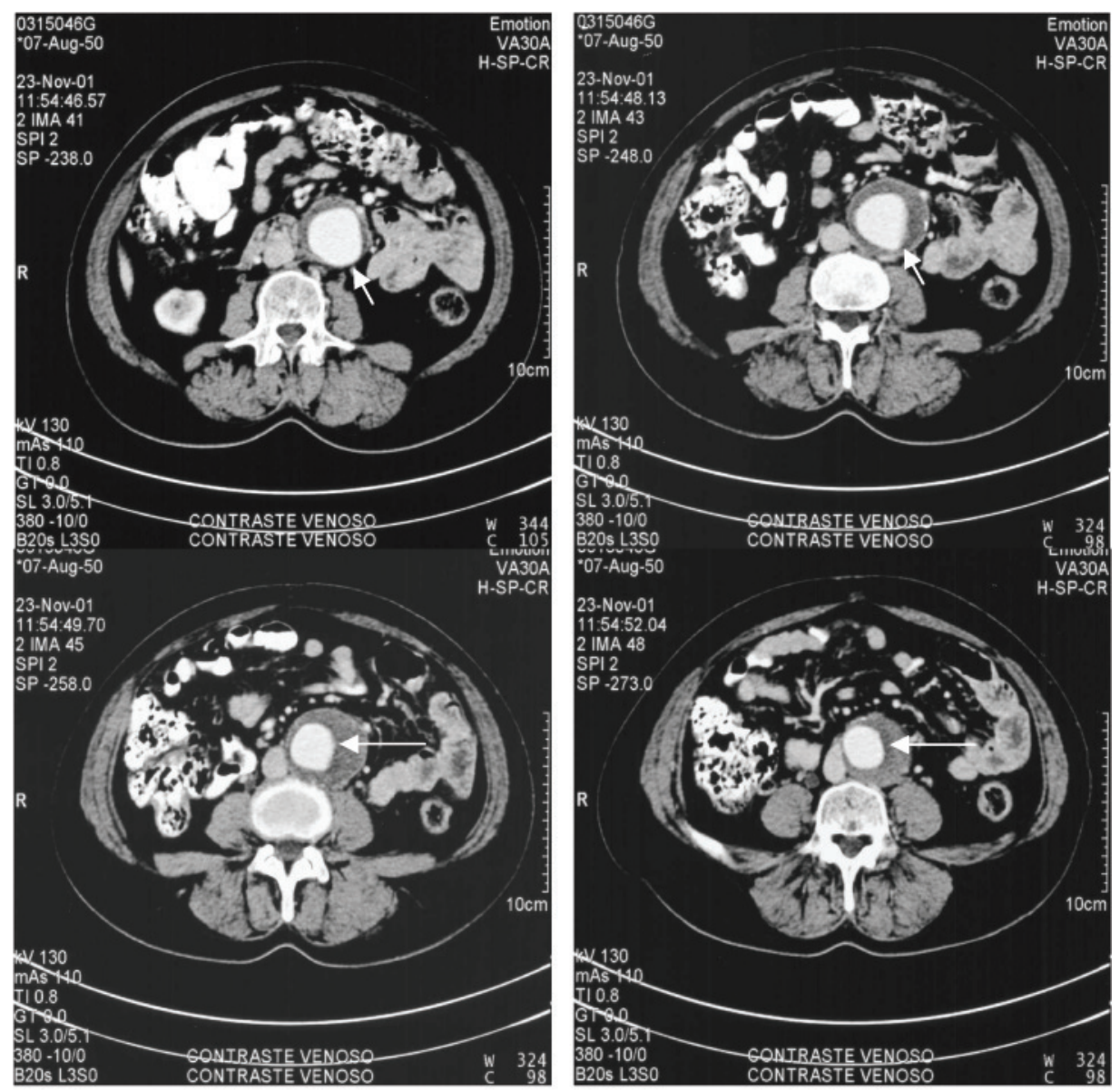

FIGURE 4 -Complex mural thrombus. The CT scan images above depicted are examples of complex mural thrombus, according with the explanation in this article. In A the residual lumen can be observed at right, in a posterior position; in B it occupies also a posterior position, but it is located at left. In $\mathrm{C}$ it is depicted an example in which the residual lumen is laterally positioned, at left; while in D it is at left, in an anterior situation. The lumen, as showed in this sequence, describes an spiral line, which implies an irregular distribution of the thrombus; opposing to the linear categories of thrombus, which can not have its clear position defined.

We found in the literature two articles assessing the position of mural thrombi on CT scans. These publications confirm the dominance of anterior wall thrombi (Table 1).

TABLE 1 - Disposition of mural thrombi.

\begin{tabular}{lccc}
\hline ILT & Pillari $^{16}(55)$ & Hans $^{17}(67)$ & Our report (100) \\
\hline Anterior wall & $50.8 \%(28)$ & $69 \%(46)$ & $53 \%(53)$ \\
Posterior wall & $7.2 \%(04)$ & $19 \%(13)$ & $11 \%(11)$ \\
Concentric & $20.0 \%(11)$ & $9 \%(6)$ & $14 \%(14)$ \\
Complex & - & - & $13 \%(13)$ \\
No thrombus & $22.0 \%(12)$ & $3 \%(2)$ & $9 \%(9)$ \\
\hline
\end{tabular}


Using the chi-square test to compare our study, individually, with the two other publications mentioned we found the following:

- when we used the same test to compare with Pillari, ${ }^{16}$ assuming the same conditions, we had $\chi^{2}=4.803983$ and $\mathrm{p}=0.186726$.

- when we compared our study with the report by Hans ${ }^{17}$ - assuming 3 degrees of freedom and a critical value for á $0.5 \%$ of 11.34 - we had $\chi^{2}=5.816868$ and $\mathrm{p}=0.120868$.

Therefore, we cannot exclude the similarity between these studies. In other words, we can say, with a reasonable degree of confidence, that the results were similar in our study and in those published reports.

\section{Discussion}

It is noteworthy, in the present study, the existence of thrombi with completely irregular disposition, leading to bizarre routes of the residual lumen.

Differently from other analyses found in the literature, we have introduced a new category in the classification of mural thrombi disposition morphology: complex thrombi. This new category is deemed necessary due to the impossibility of grouping such thrombi in harmonious patterns.

Some authors have focused on investigating the role of mural thrombi in the rupture of aneurisms, ${ }^{14}$ since such thrombi may be associated with the weakening of the aortic wall. The wall beneath the thrombus is thinner, has less and more fragmented elastic fibers, and contains higher concentrations of inflammatory cells and lower concentrations of cells regulating production of matrix components (SMC). ${ }^{15}$ Despite the relative oxygen perfusion of the thrombus, it may function as a barrier to oxygen transport, leading to hypoxia. ${ }^{14}$

Other authors suggest the mural thrombus could be a protecting factor, reducing the hemodynamic stress on the AAA wall, such reduction being more marked in large and well organized thrombi, whereas it could also be found in small ones. ${ }^{10}$

A study of 78 autopsies reported that $62 \%$ (49) of the aneurisms suffered rupture on the posterior wall. However, these authors did not associate a role of protection to the thrombus, since it was present in $80 \%$ (62) of the cases, at the site of rupture. ${ }^{18}$ Hans ${ }^{17}$ observed a dominant pattern of deposition of ILT on the anterior wall, without statistically significant difference, with respect to this distribution, between rupture and non-ruptured aneurisms.

Therefore, it seems interesting to know the disposition of ILT and subsequently establish, based on the relationship with known rupture sites, the presence or absence of thrombi and the different patterns of residual lumen, prognostic factors supported by the analysis of their morphology.

\section{Conclusion}

The formation of mural thrombi in abdominal aorta aneurisms, as shown on CT scans, seems to be predominantly located on the anterior wall of the aneurismatic mass, with the residual lumen route projecting towards the posterior wall; these findings were consistent between our study and the few reports available in the literature.

\section{References}

1. Puech-Leão P, Molnar LJ, Oliveira IR, Cerri GG. Prevalence of abdominal aortic aneurysma screening program in São Paulo, Brazil. São Paulo Med J. 2004;122,158-60.

2. Bonamigo TP, Siquiera I. Screening for abdominal aortic aneurysm. Revista HC-FMUSP. 2003;58:63-8.

3. Noel AA, Gloviczi P, Cherry KJ Jr, Bower TC, Panneton JM, Mozes GI, Harmsen WS, Jenkins GD, Hallett JW Jr. Ruptured abdominal aortic aneurysm; the excessive mortality of conventional repair. J Vasc Surg. 2001;34:416.

4. Donadson MC, Rosenberg JM, Bucknam CA. Factors affecting survival after ruptured abdominal aortic aneurysm. J Vasc Surg. 1985;2:564-70.

5. Katz DJ, Stanley JC, Zelenock GB. Operative mortality rates for intact and ruptured abdominal aortic aneurysms in Michigan: an eleven-year statewide experience. J Vasc Surg. 1994;19:804-17.

6. Dardik A, Burleyson GP, Bowman H, Gordon TA, Williams GM, Webb TH. Surgical repair of ruptured abdominal aortic aneurysm in state of Maryland: factors influencing outcome among 527 recent cases. J Vasc Surg. 1998;28:413-20; discussion, 420-1.

7. Johansen K, Kohler TR, Nicholls SC, Zierler RE, Clowes AW, Kazmers A. Ruptured abdominal aortic aneurysm: the Harboview experience. J Vasc Surg. 1991;13:240-7.

8. Gillum RF. Epidemiology of aortic aneurysm in the United States. J Clin Epidemiol. 1995;48:1289-98.

9. Harter LP, Gross BH, Callen RA, Barth RA. Ultrasonic evaluation of abdominal aortic aneurysm. J Ultrasound Med. 1982;1:315-8.

10. Wang DHJ, Makaroun MS, Webster MW, Vorp DA. Effect of intraluminal thrombus on wall stress in patient specific models of abdominal aortic aneurysm. J Vasc Surg. 2002;598-604.

11. Adolph R, Vorp DA, Steed DL, Webster MW, Kameneva MV, Watkins SC. Cellular content and permeability of intraluminal thrombus in abdominal aortic aneurysm.J Vasc Surg. 1997;25:916-26.

12. Fontaine V, Jacob MP, Houard X, Rossignol $\mathrm{P}$, Plissonnier D, Angless,-Cano E. Involvement of the mural thrombus as a site of protease release and activation in human 
aortic aneurysms. Am J Pathol. 2002;161:170110

13. Wolf YG, Thomas WS, Brennan FJ, Goff WG, Sise MJ, Bernstein EF. Computed tomography scanning findings associated with rapid expansion of abdominal aortic aneurysms. J Vasc Surg. 1994;529-35.

14. Vorp DA, Lee PC, Wang DH, Makaroun MS, Nemoto EM, Ogawa SK. Association of intraluminal thrombus in abdominal aortic aneurysm with local hypoxia and wall weakening. J Vasc Surg. 2001;34:291-9.

15. Kazi M, Thyberg J, Religa P, Roy J, Eriksson P, Hedin U, Swedenborg J. Influence of intraluminal thrombus on structural and cellular composition of abdominal aortic aneurysm wall. J Vasc Surg. 2003;38:1283-92.
16. Pillari G, Chang JB, Zito J, Cohen JR, Gersten K, Rizzo A, Bach AM. Computed tomography of abdominal aortic aneurysm. An in vivo pathological report with a note on dynamic predictors. Arch Surg. 1988;23:727-32.

17. Hans SS, Jareunpoon O, Balasubramaniam M, Zelenock GB. Size and location of thrombus in intact and ruptured abdominal aortic aneurysms. J Vasc Surg. 2005;41:584-8.

18. Simão da Silva E, Rodrigues AJ, Magalhães Castro de Tolosa E, Rodrigues CJ, Villas Boas do Prado G, Nakamoto JC. Morphology and diameter of infrarenal aortic aneurysms: a prospective autopsy study. Cardiovasc Surg. 2000;8:526-32

\section{Correspondence:}

Takachi Moriya

Department of Surgery and Anatomy

Ribeirão Preto Faculty of Medicine, University of São Paulo

Conflict of interest: none

Av. Bandeirantes 3900,

14048-900 Ribeirão Preto, SP, Brazil

Phone/Fax: (+55) 16 3602-2593

tmoryia@fmrp.usp.br

\section{How to cite this article:}

Guimarães TAS, Garcia GN, Dalio MB, Bredarioli M, Bezerra CAP, Moriya T. Morphological aspects of mural thrombi deposition: residual lumen route in infrarenal abdominal aorta aneurisms. Acta Cir Bras [serial on the Internet], 2008; 23 Suppl 1. Available from URL: http://www.scielo.br/acb.

\section{Comments:}

The interesting study proposed by the authors aims to identify the most frequent deposit location of mural thrombi in infrarenal abdominal aorta aneurisms. For this, a retrospective study was conducted involving 100 patients with abdominal aorta aneurisms, who were submitted to a tomography of the abdominal region. The results showed that $91 \%$ of the patients had mural thrombi, and 53\% of these were located on the anterior aorta wall, with irregular internal distribution and projection of the residual lumen directed to the posterior wall. The data presented confirm literature reports, but the authors suggest a new classification of "complex thrombi", that is , thrombi not fitting into a classic or harmonious standard. The authors further comment on formation of intraluminal thrombi and rupture of these aneurisms, and also on its protective role on the stress caused by blood pressure on the arterial wall. Since this manuscript contains a pertinent investigation with informative data, it should be published.

\section{Anibal Basile Filho}

Associate Professor, Division of Intensive Care Unit, Department of Surgery and Anatomy, Ribeirão Preto Faculty of Medicine, University of São Paulo, Brazil. 